\title{
LA ACCIÓN COLECTIVA PARA FRENAR EL DETERIORO FORESTAL DE MONTE ALTO, VALLE DE BRAVO, MÉXICO
}

\author{
COLLECTIVE ACTION TO STOP FOREST DEGRADATION \\ MONTE ALTO, VALLE DE BRAVO, MEXICO
}

\author{
María de Lourdes Cárcamo Solís ${ }^{(*)}$ \\ Arminda Ruiz González ${ }^{(*)}$ \\ María Mercedes León Sánchez ${ }^{(* * *)}$
}

\begin{abstract}
Resumo: Esta pesquisa demonstra a importância da ação coletiva ambientalista na definição de uma política pública. Pode se observar como a raiz da crise florestal em Monte Alto Valle de Bravo, a sociedade civil da região (Biocenosis, A. C.; "Los Intocables", A. C.; El Fondo Valle de Bravo Solidaridad, A. C.; o Patronato ProValle de Bravo, A. C.; e o Promotor Ambientalista Leopoldo Valdez Cruz) começou a pressionar por meio de ações coletivas que levaram o governo estadual e municipal a tomar medidas na região. Desta forma, se expressa uma vez que a cidadania adotou uma nova maneira de representação que se manifesta nos bens coletivos na falta de ações públicas no México. Este trabalho responde à pergunta da pesquisa: "até que ponto a ação coletiva em Valle de Bravo foi uma clara manifestação da ausência de uma política ambientalista que permita um desenvolvimento sustentável na região?" Os objetivos desta pesquisa se centraram nas características das ações coletivas na região e a proposta florestal em Monte Alto, Valle de Bravo, México, surgida destas ações. A metodologia foi pesquisa-participativa mediante sondagem por redes, conhecida como "bola de neve ", que consistiu em assistir as diversas assembleias participativas e a realização de enquetes sobre a avaliação das diferentes organizações sobre a crise ambiental e suas soluções. Esta pesquisa comprovou a relevância da ação coletiva em Valle de Bravo, para mudar os esquemas de exploração do meio ambiente; no entanto, observa-se que na região existem múltiplas expectativas econômicas na exploração privada da madeira que se contrapõem aos interesses comunitários e estes interesses questionam as ações dos governos locais ambivalentes na região.
\end{abstract}

Palavras-chave: Sociedade civil; Terceiro setor; Ação coletiva; Monte Alto declínio florestal; Governo.

(*) Profesora Investigadora del Departamento de Estudios Multidisciplinarios de la Sede Yuriria, Campus Irapuato-Salamanca de la Universidad de Guanajuato. E-mail: <carcamo.lulu@gmail.com> y < mlcarcamo@ugto.mx>.

$(* *)$ Profesora en el Área de Humanidades. Tecnológico de Monterrey Campus Toluca. E-mail: < $\underline{\operatorname{arminda} @ i t e s m . m x>.}$

$(* * *)$ Profesor-Investigador, Departamento de Arte y Empresa, División de Ingenierías del Campus Irapuato-Salamanca, Universidad de Guanajuato. E-mail: <mleon@ugto.mx>. Recebido em 1o.02.2013 e aceito em 08.05.2013. 
Abstract: This research shows the importance of the environmentalist collective action in the definition of public politics. It is observed how on the forest basis in Monte Alto Valle de Bravo, the regional civil society (Biocenosis, A.C. ${ }^{(1)}$; "Los Intocables", A. C.; El Fondo Valle de Bravo Solidaridad, A. C.; El Patronato Pro Valle de Bravo, A. C.; and the Environmental Promoter, Leopoldo Valdez Cruz), made pressure through the collective actions which led the state and local government to get involved in this region. This is how, once again, people have chosen a new way of representation, which is manifested in the collective goods towards the absence of public actions in Mexico. This paper responds to the research question about, To what extend does the collective action in Valle de Bravo was a clear manifestation of the absence of the environmentalist politics that allows a sustainable development in the region? The objectives of this research are focused on the characteristics of the collective actions in the region and the forest proposal in Monte Alto, Valle de Bravo, and Mexico suggested from these actions. The methodology was based on participative-research through the probing on social networks known as the snowball, which consisted on attending to the different participative assemblies; the realization of surveys about the evaluation of the different organizations about the environmental crisis, and its solutions. This research proved the collective action relevance in Valle de Bravo, for changing the exploration schemes of the environment. Nevertheless, the existence of multiple economic expectations in the private exploitation of wood is observed, which are contrasted with the communitarian interests and these interests have questioned the actions of the local ambivalent governments in the area.

Keywords: Civil society; Third sector; Collective action; Monte Alto Forest decline; Government.

\section{INTRODUCCIÓN}

Valle de Bravo es una de las regiones más importantes en materia forestal del estado de México, y una parte importante de las zonas forestales de México. Debido a su crecimiento urbano-turístico, la zona original hoy se encuentra reforestada por diferentes tipos de árboles. El mal manejo del ecosistema ha llevado a una crisis ambiental en la región que ha implicado el surgimiento de plagas y enfermedades de sus bosques originales principalmente bosques de pino y oyamel.

Los asentamientos humanos irregulares, el crecimiento urbano, el uso de suelo para fines agrícolas, incendios forestales, plagas y enfermedades, así como la tala clandestina en la región han afectado la ecología original y han generado un gran deterioro en la región de los llamados bosques de agua.

En particular en la zona de Monte Alto, localidad comprendida en la microrregión I de Valle de Bravo, en el estado de México (México), es un área natural protegida (ANP, si es en plural es ANP's) a partir de 1991 y se estableció un manejo forestal diseñado tanto por autoridades federales como estatales, el cual incluía regeneración, protección, restauración, conservación, producción, cultivo, ordenación y servicio de la región. Para 2005 se expropió una parte de la región con fines de recuperación. Como una proporción importante de los bosques en México son de propiedad comunal o ejidal, esto ha dado origen a la agrupación colectiva para dar respuesta a las crisis ambientales ${ }^{(2)}$. Hasta la

(1) A. C. en español es asociación civil; es English A. C. es civil association; en Português A. C. é associação civil.

(2) "Más del 90\% de la población indígena vive en áreas boscosas, tanto tropicales como templadas y el resto habita en regiones áridas y semiáridas (Toledo 1998). De acuerdo con este autor, poco más de dos tercios de las unidades rurales 
fecha se desconoce los alcances de este programa de manejo de los recursos en la zona ya que existen inventarios limitados de los recursos forestales y ninguna a nivel de censo.

Debido a ello, y a la falta de un programa general en la región que establezca prioridad en el desarrollo sustentable de la región, han surgido diversas organizaciones en aras de la protección ambiental.

Este trabajo analiza las acciones colectivas que permitieron abrir un espacio público que coadyuvara a la construcción de la política forestal en Valle de Bravo, México, como resultado de la problemática forestal existente en el ANP Monte Alto. La elección del lugar fue debido a las acciones colectivas realizadas por los residentes en 2010 a raíz de los conflictos generados entre los propietarios y los asentamientos irregulares y de la degradación del medio ambiente en esta localidad.

Las acciones colectivas son manifestaciones de una colectividad para resguardar un bien o interés común, que han comenzado a generalizarse en algunos países de América Latina ${ }^{(3)}$ tales como Ecuador, Brasil, Venezuela, Chile, Argentina, como parte de las acciones que contribuyen al desarrollo de una política pública en particular en materia ambiental. Por ello se observa el surgimiento de organizaciones civiles como formas de gestión ciudadana que contribuyan a la conservación de las ANP's.

En la medida en que los latinoamericanos fueron democratizando sus procesos políticos, las acciones colectivas han jugado un papel fundamental en la conformación de una ciudadanía ampliada, al grado tal que dichas acciones colectivas han comenzado a tener una figura jurídica en el marco legislativo de países como Brasil, Venezuela, Chile y Uruguay ${ }^{(4)}$.

En este sentido, López Maya y Lander (2006) analizan cómo la movilización popular en Venezuela ha estado presente incluso desde la época en que se consideraba a este país como una de las democracias más estables de América Latina.

Un informe dado a conocer por el Programa de Naciones Unidas para el Desarrollo (PNUD) titulado "La protesta social en América Latina publicado en 2013" afirma que las protestas sociales caracterizan a esta región más que cualquier otra parte del mundo y muestran un alto grado de participación popular, este informe también muestra como Bolivia, Perú y Argentina como países con mayor incidencia en movilizaciones sociales ${ }^{(5)}$. También señala que los temas primordiales en estas movilizaciones fueron: educación, medio ambiente, salud, trabajo y derechos humanos.

de producción del país son propiedad comunal indígena y representan cerca del $50 \%$ del territorio mexicano, $70 \%$ de las áreas boscosas y $80 \%$ de la tierra dedicada a la agricultura. Entre el $70 \%$ y el $80 \%$ del bosque en México está bajo la administración de entre 7,000 y 8,000 ejidos y comunidades." (Larson y Sarukán, 2003 :12)

(3) En Argentina existen diversas publicaciones que dan cuenta de las acciones colectivas en este país: protección ambiental. Destaca el estudio de Merlinski (2008), quien menciona cómo a raíz del movimiento de piqueteros en Argentina han proliferado acciones de carácter esporádico, manifestaciones de un grupo pequeño poco estructurado, que buscan definir o proteger un interés común y su papel en la definición de políticas ambientales.

(4) En materia de Derecho Ambiental, Escudero (2010) señala que en Estados Unidos las class actions se regulan en Rules of Civil Procedure, en Colombia se tiene la figura de la acciones populares desde a rango constitucional desde 1998, en países como Brasil, Venezuela, Chile, Uruguay existen figuras para la protección de derechos colectivos, mientras que México esta legislación recientemente fue aprobada pero en términos muy generales desde agosto de 2011.

(5) El informe examinó más de 2300 protestas sociales entre octubre de 2009 y septiembre de 2010. 
Las acciones colectivas y la red establecida entre las organizaciones ambientalistas en Monte Alto han conformado una nueva perspectiva para enfrentar las crisis ambientales no sólo en esta ANP, sino también en el municipio de Valle de Bravo. El Estado juega un papel clave para la preservación de la riqueza forestal del ANP pero sus resultados no han sido todavía satisfactorios para resolver dicha problemática.

Metodológicamente este trabajo se apoyó en un estudio de naturaleza cualitativa y cuantitativa realizado de 1997 a 2010; en dicho periodo se hicieron más de 30 visitas que recolectaron los significados e interpretaciones de la cooperación entre los diferentes actores para resolver una problemática de índole pública. La elección del lugar obedeció a las acciones colectivas que surgieron a raíz de las crisis ambientales. Se diseñó el instrumento de recopilación de información de campo, con entrevistas a profundidad llevadas a cabo con seis de las ocho organizaciones ambientalistas localizadas en Valle de Bravo. Posteriormente se les aplicó un cuestionario con preguntas cerradas y abiertas para precisar datos, cifras y significados. Este mismo procedimiento se siguió con las entidades gubernamentales dedicadas a la preservación y protección del medio ambiente, ubicadas en el Distrito Federal, Toluca y Valle de Bravo ${ }^{(6)}$.

Además se desarrolló un grupo de enfoque denominado "Megaproyecto de Preservación de Monte Alto y sus Recursos Naturales", donde se reunieron, tanto las organizaciones ambientalistas, como las autoridades del gobierno Federal (Secretaría del Medio Ambiente y Protección al Medio Ambiente, SEMARNAP ${ }^{(7)}$, y la Procuraduría Federal de Protección al Medio Ambiente, PROFEPA); Estatal (Comisión Estatal de Parques Naturales y de la Fauna, CEPANAF), y Municipal (La Protectora de Bosques, PROBOSQUE, de Valle de Bravo. Esta reunión se llevó a cabo con la finalidad de recoger y evaluar por parte del gobierno municipal y federal la experiencia y demandas que las organizaciones ambientalistas tuvieran en materia de política forestal, para definir acciones en esta ANP.

Por último, se aplicó una encuesta con preguntas cerradas a 301 habitantes de las localidades vecinas al ANP: área de amortiguamiento de Monte Alto, Tres Puentes, Rincón de Estradas, Loma de Chihuahua, Loma de Rodríguez, San Mateo Acatitlán y Valle de Bravo; mediante un muestreo aleatorio estratificado simple, con el fin de cruzar la información aportada por las organizaciones ambientalistas y los habitantes de estas comunidades con respecto a las medidas de preservación forestal practicadas en la región. Esta información fue sistematizada estadísticamente para complementar el estudio cualitativo que permitió tipificar las acciones colectivas en la preservación y protección del ANP.

\section{TEORÍA DE LA ACCIÓN COLECTIVA}

La sociedad civil también se le conoce como el "tercer sector" que abarca el universo organizacional que emerge en muchas sociedades entre el gobierno y el mercado. Su definición

(6) Cabe señalar que esta es una zona altamente contaminada de México por problemas de crecimiento urbano y uno de los focos de mayor atención por el número de habitantes implicados en este problema (debido a que la ciudad de México ha crecido en sus alrededores junto con el Estado de México, su crecimiento ha sido sobre zonas boscosas. Según datos de PRONATURA el Estado de México (incluye la zona de Valles de Bravo) es una de las regiones con mayor deforestación en México (El Milenio, 20 de mayo de 2013).

(7) Antecedente de la SEMARNAT (Secretaría del Medio Ambiente y Recursos Naturales). 
abarca características como: es organizada, privada (institucionalmente separada del gobierno), es auto-gobernada, genera repartos sin fines de lucro entre la población en desventaja y su formación no tiene un carácter obligatorio para sus miembros que lo componen (Cohen y Arato, 1995). El estudio del tercer sector forma parte de la Teoría Política Moderna y es la base del concepto teórico de la sociedad civil cuya aplicación aparece justo para definir la participación colectiva de la ciudadanía en procesos democráticos, donde el gobierno y las organizaciones sociales participan activamente en la política. El concepto de tercer sector surge como producto de los ideales utópicos de la modernidad: libertad, igualdad, democracia, solidaridad y justicia (Cohen y Arato, 1995).

El tercer sector provee educación, salud, cuidado del medio ambiente y servicios sociales que los gobiernos proporcionan con grandes deficiencias, que los ha llevado a una constante ingobernabilidad, con lo cual se da comienzo a formas concretas de organización de la sociedad civil.

El tercer sector desarrolla su potencial positivo cuando logra detonar en la arena pública la acción colectiva que se traduce en alianzas, pactos y acuerdos, que permitan el logro de objetivos comunes de diferentes grupos y sectores sociales, respetando el pensamiento plural y la autonomía de las organizaciones sociales.

De acuerdo con Habermas (1990) las acciones colectivas han adquirido dos tipos de funciones bien identificadas. Primero, estos movimientos se desarrollan como componentes dinámicos de la sociedad civil, promueven el aprendizaje social y construyen una identidad propia, que les permite activar el potencial de las tradiciones culturales y los nuevos procesos de socialización. En segundo plano, los movimientos que promueven proyectos democráticos, despliegan la posibilidad de activar el espacio público.

Habermas (1990) analiza a las acciones colectivas como meros elementos organizados mediante estrategias defensivas que les permiten protegerse del proceso de reificación fomentado por la racionalización instrumental del gobierno y la economía.

Las acciones colectivas han sido objeto de análisis desde diferentes áreas disciplinares. A lo largo del siglo pasado se fueron reconociendo los espacios importantes de estas acciones: construcción de redes de apoyo, promotor del cambio, expresión de lo público, foro de formación de una ciudadanía con mejores perspectivas de participación en particular cuando se reconoce al conflicto, disenso y discusión como expresiones culturales (Ruiz, 2011).

Una de las percepciones que contribuyó a una conceptualización racional de las acciones colectivas fue la de Olson (1999) en la que se extrema el cálculo de los beneficios que puede obtener un actor al emprender una acción colectiva. Esta nueva perspectiva puso a esta temática en el área disciplinar de la sociología y economía.

En efecto, en el análisis microeconómico las acciones individuales se explicaban bajo las expectativas racionales; no obstante cuando se habla de la acción colectiva no existe una relación directa, pues se trata de incorporar al análisis la idea de que los individuos aislados quieren conseguir el mejor resultado de acuerdo con sus preferencias al involucrarse en decisiones colectivas. Esta idea no parecía tener una relación tan precisa dado el llamado "contagio" de las masas. Así, el planteamiento de Olson (1999) rompe con esa idea y queda inscrito dentro de la teoría de la decisión racional, con lo que para muchos autores resolvía el problema del tránsito entre lo individual y lo social. 
Toda organización desempeña su función cuando hay intereses comunes, sin embargo lo hace con referencia al mercado competitivo. Esta acción colectiva existe en la medida en que existen bienes públicos que se comparten, es decir, la obtención de un beneficio general al actuar de manera colectiva ${ }^{(8)}$.

La aproximación de Olson pretende analizar la forma en que los individuos llegan racionalmente a establecer acciones colectivas. Su argumento principal es la existencia de intereses comunes, o al menos problemáticas comunes, y la idea de resolverlas en conjunto, pero en particular la existencia de un bien público, que puede convertirse en privados para quien no actúe con el conglomerado (la exclusión): la acción colectiva sería resultado de los incentivos selectivos que existan para la participación en la acción.

La acción colectiva como marco de la toma de decisiones racional ha dado paso a los planteamientos sobre la ciudadanía ampliada, en el momento en que se habla de que el ciudadano no debe ser excluido de la participación pues es reflejo de la colectividad. Esto puede dar mayor espacio al juego de la ciudadanía en la toma de decisiones lo que conduce a la idea de una democracia, no directa, con acciones más estructuradas bajo el papel de las organizaciones de la sociedad civil (OSC). Se distingue de la política porque carece de la intención de tomar el poder, aunque es finalmente vista como una "comunidad política" (Bizberg, 2007).

Las OSC pueden convertirse en aliadas de la política pública si cumplen con alguna de las siguientes funciones (Tapia, 2011, p. 420):

a) Fomentar la transferencia y la rendición de cuentas del gobierno al vigilar el desempeño de los funcionarios públicos y ser una fuente de información independiente sobre el diseño y los resultados de las políticas públicas. En este sentido incluso existen organizaciones de la sociedad civil que cumplen esta función exprofeso.

b) Garantizar los derechos humanos y el Estado de derecho al monitorear y establecer los límites al abuso de poder y garantizar al Estado de derecho de un régimen democrático.

c) Contribuyen a la formación, financiamiento y la prestación de servicios públicos. Las OSC complementan servicios públicos que el Estado ya brinda.

d) Promueven la participación de los sectores más pobres en las políticas públicas y la toma de decisiones. Incorporan a más actores privados a la esfera pública.

e) Gestionan proyectos particulares (como ha sido reciente el caso de los parques ecológicos). El parque bicentenario en Toluca, estado de México, fue una muestra clara de un intento por establecer un lugar donde se discutan acciones gubernamentales por organismos de la sociedad civil.

(8) Olson (1999: p. 24 - 25) señala: "a los beneficios comunes o colectivos proporcionados por los gobiernos, los economistas les llaman normalmente "bienes públicos", el concepto de bienes públicos es una idea más antigua e importante en el estudio de las finanzas públicas. Un bien común, colectivo o público se define aquí como un bien cualquiera tal que si una persona $\mathrm{X}$, que forma parte de un grupo lo consume, no puede serle negado a los otros miembros de ese grupo. Dicho de otra forma, aquellos que no compran o no pagan alguno de los bienes públicos o colectivos no pueden ser excluidos o impedidos de participar en el consumo de ese bien, como si puede serlo cuando se trata de bienes no colectivos". 
Por su parte, Somuano (2010) señaló que este debate ha sido seguido por los mismos organismos internacionales quienes han expresado un nuevo interés hacia las OSC para promover sus funciones a nivel local. Bajo este esquema surgió este tipo de organizaciones bajo el amparo de organismos internacionales (World Bank, 1997) lo que dio un peso distinto al concepto de participación ciudadana.

En la década de los noventas proliferaron las organizaciones civiles y sociales en diversas áreas de acción y continuaron formándose redes que aglutinaban a varias organizaciones en toda América Latina. Un cambio importante en esta década es que las organizaciones ya no solamente trabajaban para el beneficio de los necesitados, ni como intermediario del gobierno, ahora se proponía trabajar con el gobierno en la gestión de proyectos sociales (Verduzco, 2001).

\section{CAusas del Deterioro forestal del ANP de Monte Alto}

Monte Alto es un área definida como ANP ubicada en Valle de Bravo, México. Cuenta con 575 hectáreas y es considerada una de las ANP más importante no sólo por su extensión y cercanía con la cabecera municipal, sino por su belleza, riqueza forestal y producción de agua (mapa 1)

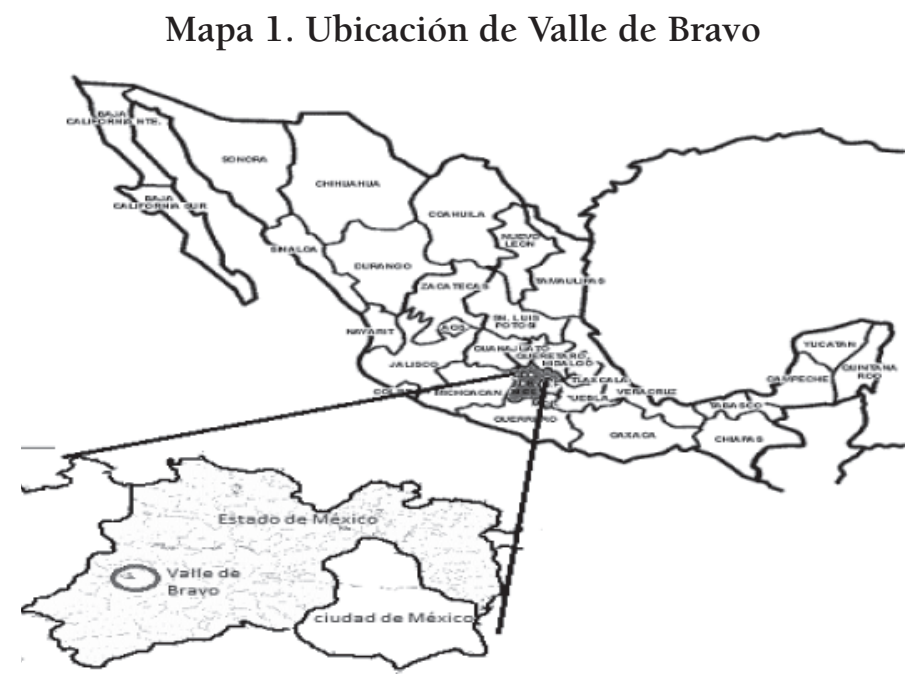

Fuente: Elaboración de las autoras.

El 75\% del agua potable que utiliza Valle de Bravo proviene de Monte Alto ${ }^{(9)}$. Una de las condiciones fundamentales que hacen posible la producción de agua, oxígeno y

(9) Tres microcuencas forman parte de Monte Alto: Cañada de Santa María, Río los Tizates y el Río del Molino, que forman la cuenca hidrológica de este lugar. El agua potable que produce Monte Alto proviene de dos fuentes: 1) El manantial "El Crustel", que atraviesa la reserva de Monte Alto, el cual surte, en promedio 20 litros por segundo de agua potable al norte del pueblo de Valle de Bravo. 2) El manantial "Los Álamos", ubicado en el sur de Monte Alto que suministra 100 litros de agua potable por segundo a los tanques de almacenamiento, que canalizan agua a la localidad de Avándaro y a las partes sur y centro del poblado de Valle de Bravo. Véase Biocenosis, A. C. (2001). Informe anual. (p. 8). Valle de Bravo, Estado de México. 
la regulación del clima, es su abundante riqueza forestal y en general, de toda la Cuenca de Valle de Bravo ${ }^{(10)}$.

Sin embargo, la región ha sido afectada por un conjunto de fenómenos causales que se entrelazan para explicar esta compleja problemática: 3.1) Conflictos históricos por la tenencia de la tierra; 3.2) el impacto socioeconómico que generó la construcción de una presa en Valle de Bravo; 3.3) el decreto expropiatorio de fecha 19 de agosto de 1991, para preservación ambiental, cuyo resultado fueron más asentamientos humanos irregulares en el ANP; 3.4) las adversas condiciones socioeconómicas de las comunidades vecinas; y, 3.5) las soluciones que aportó el Estado en materia de políticas y leyes ambientales fueron ineficientes e ineficaces para contrarrestar la problemática forestal de Monte Alto.

\subsection{CONFLICTOS HISTÓRICOS POR LA TENENCIA DE LA TIERRA}

Con respecto al primer fenómeno, en 1947 el Departamento Agrario llevó a cabo un proceso de deslinde en Valle de Bravo por 3,178-70 hectáreas de las cuales 2,334-50 se asignaron a la conformación de la comunidad "La Cabecera y sus Barrios Santa María Ahuacatlán, Otumba y la Peña", con el objetivo de resolver el conflicto comunal derivado de la invasión de 134-60 has que realizaron los pobladores de San Mateo Acatitlán, afectando la propiedad de 57 comuneros de la Cabecera ${ }^{(11)}$. Del total de hectáreas destinadas a la Cabecera y sus Barrios, se destinaron 2,283-20 hectáreas para Monte Alto. El proceso de deslinde iba de acuerdo con la idea derivada de la Revolución Mexicana de 1910 sobre que el Estado tenía la obligación de otorgar tierras a los desposeídos. De este modo, el Estado fomentó la práctica de entregar tierras a sectores desposeídos, lo cual se hizo con fines electorales (clientelismo) para mantener el poder gubernamental del partido oficial, siendo ésta otra de las razones del deslinde que se muestra en el Cuadro I.

\section{Cuadro I. Distribución de la tenencia de la tierra}

\begin{tabular}{|l|c|}
\hline \multicolumn{1}{|c|}{ Distribución de la tenencia de la tierra } & $\begin{array}{c}\text { Hectáreas-áreas, } \\
\text { respectivamente }\end{array}$ \\
\hline Terrenos de riego vendidos a la Comisión Federal de Electricidad & $658-50$ \\
\hline Zona urbana & $51-10$ \\
\hline Zona invadida por los vecinos de Acatitlán & $134-60$ \\
\hline -Tierras de uso comunal de la Cabecera y sus tres barrios & $2,334-50$ \\
-Tierras de Monte Alto dentro de los terrenos de la Cabecera & $2,283-20$ \\
-Tierras sin cultivar ni labrar dentro de los terrenos de la cabecera & $51-30$ \\
\hline Total de superficie deslindada & $3,178-70$ \\
\hline
\end{tabular}

Fuente: Diario Oficial, jueves 18 de septiembre de 1947, Departamento Agrario; México.

(10) La vegetación predominante en Monte Alto está caracterizada por la presencia de tres tipos de ecosistemas: el bosque de pino-encino, el bosque mesófilo de Montaña y la vegetación de humedales.

(11) Un grupo de vecinos de la cabecera levantó un acta el 17 de mayo de 1943, denunciando la invasión de los pobladores de Acatitlán sobre tierras comunales. La disputa de 134-60 has se debió a la indefinición de los derechos de uno y de otro sector de población, por lo que se ratificó que el litigio de esta propiedad se resolvió a favor de los pobladores de Acatitlán. Ello debido a dos razones fundamentales: al factor económico-social, en el que estos pobladores han tenido una mayor necesidad de la tenencia de la tierra y, al factor socio histórico, debido a la ancestral disputa por el terreno DOF (jueves 18 de septiembre de 1947). 
El auge del turismo debido a la construcción de la Presa de Valle de Bravo, provocaron la venta de tierras con documentos irregulares con lo que se fomentó el tráfico inmobiliario y especulativo que propició asentamientos humanos irregulares no sólo en Monte Alto, sino también en todo Valle de Bravo.

\subsection{EL IMPACTO SOCIOECONÓMICO QUE GENERÓ LA CONSTRUCCIÓN DE UNA PRESA EN VALLE DE BRAVO}

En julio de 1947 se construyó una presa en Valle de Bravo con el objetivo de impulsar el crecimiento económico de la zona, lo que propició: a) la creación de empleos y el fomento del turismo, b) la construcción de casas y residencias, cuyo efecto fue el incremento de la deforestación de grandes extensiones de bosques - principalmente las de Monte Alto por el atractivo panorámico, c) la venta de tierras con documentos irregulares con lo que se fomentó el tráfico inmobiliario y especulativo que propiciaron asentamientos humanos irregulares, y d) la generación de electricidad, que hizo posible un importante crecimiento inmobiliario en la zona, aunque a un costo ambiental considerable.

\subsection{EL DECRETO EXPROPIATORIO DE FECHA 19 DE AGOSTO DE 1991 PARA PRESERVACIÓN AMBIENTAL}

El decreto del 19 de agosto de 1991, no nada más permitió expropiar de la comunidad "La Cabecera y sus Barrios" las 677 hectáreas para preservación ecológica, sino también 329 hectáreas a favor de la SEDUE (Secretaría de Desarrollo Urbano y Ecología) ${ }^{(12)}$ para destinarlas como reservas territoriales para la conservación de Valle de Bravo. Asimismo, según acuerdo convenido entre la SEDESOL (Secretaría de Desarrollo Social) y el gobierno del estado de México ${ }^{(13)}$, se autorizó a la CORETT (Comisión de Regularización de la Tenencia de la Tierra) expropiar otras 431 hectáreas de tierras de la misma comunidad ${ }^{(14)}$, con el objetivo de eliminar la ilegalidad de la tenencia de la tierra. Sin embargo, estos esfuerzos por tratar de limitar los asentamientos humanos irregulares, conservar y ampliar la superficie de Monte Alto, no se han llevado a cabo, pese a las presiones de la sociedad civil debido a que se encuentran en juego intereses económicos y políticos de la región de ciertos sectores privilegiados

\subsection{LAS ADVERSAS CONDICIONES SOCIOECONÓMICAS DE LAS COMUNIDADES VECINAS}

En lo que se relaciona al ámbito socieconómico de las comunidades vecinas, la principal causa del deterioro forestal de Monte Alto, son las condiciones socioeconómicas desfavorables en que viven las comunidades colindantes: Valle de Bravo, el área de amortiguamiento

(12) Nombre de la secretaría hasta antes de 1992, fue creada en 1982 y se consideró el primer paso hacia una política federal ambiental definida, después se convirtió en lo que hasta hoy se conoce como SEDESOL al aplicarse el concepto de desarrollo sustentable. Esta secretaría quedó encargada de indemnizar a los pobladores de la Cabecera y sus Barrios por una cantidad de \$2.961.324.999,00.

(13) Véase Periódico Oficial del gobierno Constitucional del estado de México de fecha 12 de septiembre de 1991. Además consúltese gobierno del estado de México, Secretaría de Desarrollo Urbano y Obras Públicas, Comisión para la Regularización del Suelo del estado de México (1o de septiembre de 1994). Panorámica General de la Problemática de la Cabecera y los Barrios Santa María Ahuacatlán, Otumba y la Peña del municipio de Valle de Bravo.

(14) Asimismo, la CORETT indemnizó a esta comunidad por la expropiación de otras 431 hectáreas de tierras, por las cuales recibieron la cantidad de \$2589857000,00. 
de Monte Alto, Tres Puentes; Loma de Rodríguez, Loma de Chihuahua, San Mateo Acatitlán y Rincón de Estradas.

Asimismo, en 2010 estas localidades mantuvieron algún grado de marginación social según datos del CONEVAL (Consejo Nacional de Evaluación de la Política de Desarrollo Social) ${ }^{(15)}$ (cuadro II), aunque en algunos casos éste disminuyó de nivel, pero su condición de rezago no desapareció. Otro aspecto crítico es la carencia de servicios de salud, se habla de rezagos en este rubro de un $40 \%$. Esta marginación hizo de Monte Alto un ANP sujeta a la tala clandestina, a los asentamientos humanos irregulares, a la práctica de incendios, a las enfermedades y plagas, a los cambios de uso de suelo, a la dilapidación de recursos no maderables, como los hongos, flores, arbustos, frutillas y plantas medicinales; que en conjunto definen lo que es la deforestación y la degradación forestal. La mayoría de estos factores están vinculados a la precariedad de sus economías locales, cuyo rezago se debe a que han sido excluidas de la política económica perfilada por la globalización.

\section{Cuadro II. Indicadores de marginación.}

Siete localidades de Valle de Bravo, Estado de México, México (2005-2010)

\begin{tabular}{|c|c|c|c|c|c|c|c|c|c|c|c|c|c|c|c|c|}
\hline \multirow[t]{2}{*}{ Localidad } & \multicolumn{2}{|c|}{$\begin{array}{c}\text { Población } \\
\text { de } 15 \text { años } \\
\text { o más anal- } \\
\text { fabeta }\end{array}$} & \multicolumn{2}{|c|}{$\begin{array}{l}\text { Población } \\
\text { de } 6 \text { a } 14 \\
\text { años que } \\
\text { no asiste a } \\
\text { la escuela }\end{array}$} & \multicolumn{2}{|c|}{$\begin{array}{l}\text { Población } \\
\text { de } 15 \text { años } \\
\text { y más con } \\
\text { educación } \\
\text { básica } \\
\text { incompleta }\end{array}$} & \multicolumn{2}{|c|}{$\begin{array}{l}\text { Población } \\
\text { sin } \\
\text { derecho- } \\
\text { habiencia } \\
\text { a servicios } \\
\text { de salud }\end{array}$} & \multicolumn{2}{|c|}{$\begin{array}{l}\text { Viviendas } \\
\text { con piso } \\
\text { de tierra }\end{array}$} & \multicolumn{2}{|c|}{$\begin{array}{l}\text { Viviendas } \\
\text { que no } \\
\text { disponen } \\
\text { de ex- } \\
\text { cusado o } \\
\text { sanitario }\end{array}$} & \multicolumn{2}{|c|}{$\begin{array}{l}\text { Viviendas } \\
\text { que no } \\
\text { disponen } \\
\text { de agua } \\
\text { entubada } \\
\text { de la red } \\
\text { pública }\end{array}$} & \multicolumn{2}{|c|}{$\begin{array}{c}\text { Viviendas } \\
\text { que no } \\
\text { disponen } \\
\text { de drenaje }\end{array}$} \\
\hline & 2005 & 2010 & 2005 & 2010 & 2005 & 2010 & 2005 & 2010 & 2005 & 2010 & 2005 & 2010 & 2005 & 2010 & 2005 & 2010 \\
\hline Valle de Bravo & 8 & 6 & 4 & 3 & 43 & 38 & 67 & 41 & 5 & 4 & 7 & 1 & 3 & 1 & 2 & 1 \\
\hline Rincón de Estradas & 13 & 19 & 6 & 29 & 76 & 70 & 65 & 34 & 13 & 8 & 45 & 24 & 9 & 16 & 32 & 24 \\
\hline Tres Puentes & 22 & 10 & 19 & 1 & 67 & 60 & 73 & 39 & 10 & 15 & 65 & 16 & 15 & 24 & 55 & 18 \\
\hline San Mateo Acatitlán & 17 & 18 & 6 & 3 & 64 & 63 & 68 & 49 & 29 & 16 & 34 & 24 & 18 & 18 & 35 & 25 \\
\hline Loma de Rodríguez & 28 & 17 & 0 & 8 & 75 & 60 & 75 & 59 & 34 & 13 & 55 & 15 & 10 & 7 & 48 & 11 \\
\hline Loma de Chihuahua & 24 & 6 & 10 & 7 & 71 & 61 & 79 & 76 & 24 & 12 & 33 & 32 & 16 & 26 & 31 & 32 \\
\hline Monte Alto & 8 & 9 & 6 & 4 & 42 & 39 & 71 & 36 & 13 & 12 & 15 & 11 & 4 & 5 & 8 & 10 \\
\hline
\end{tabular}

Fuente: Elaboración de las autoras a partir de datos de CONAPO, 2010.

Un ejemplo de ello, lo representó el desempleo en estas comunidades: Loma de Rodríguez, con un 11\%; Valle de Bravo, 6\%; San Mateo Acatitlán, 5\% y las demás localidades entre 1 y $2 \%$, en 2010 , de acuerdo con la información proporcionada por el Instituto Nacional de Estadística, Geografía e Informática (INEGI).

En promedio, las siete localidades mostraron que el 68\% de su población ocupada recibió el salario mínimo real que va de $\$ 10.10$ a $\$ 50.50$ pesos diarios a precios de 1994 , es decir, ganaron entre uno a cinco salarios nominales. En términos reales, los ingresos de estas localidades perdieron cerca del $70 \%$ de su poder de compra, debido a la inflación y a la contención salarial, en 2010. Estas percepciones se lograron en actividades agropecuarias, comercio y servicios de bajo valor agregado que no les permitieron una obtención significativa de ingresos reales.

En cuanto al crecimiento de la población, durante el periodo comprendido entre 1990 y 2010, sobresale Loma de Rodríguez con 11\% como crecimiento promedio anual;

(15) Organismo creado para la información sobre la política social y detección de la pobreza, es un organismo descentralizado de la autoridad federal. 
Loma de Chihuahua, 5.6\% y el área de amortiguamiento de Monte Alto, con un 6.3\%, lo que significa que estas localidades fueron las que más contribuyeron al deterioro forestal por la presión poblacional.

El principal problema forestal de Monte Alto es la extracción de madera y leña. Para estimar la magnitud de la extracción de leña Biocenosis, A. C. realizó algunos estudios en 1996, y llegó a contabilizar que en ese año se talaron cerca de 1800 a 2000 árboles, es decir, cinco árboles diarios en promedio.

Además, en enero del 2005 se realizó un inventario forestal para calcular el volumen de madera en pie y el de madera tirada. Para tal efecto, se zonificó a Monte Alto en cuatro rodales y 30 subrodales. Del inventario, se concluyó que la extracción de madera y leña sobrepasan en un 300\% la capacidad de reforestación. Los volúmenes totales de madera, con los que cuenta esta ANP son mayores a 44,356.304 metros cúbicos, considerando que produce madera en 1\% de incremento promedio anual (443.56 metros cúbicos anuales), y se demanda anualmente 1,204.5 metros cúbicos, por lo tanto, existe una sobreexplotación de madera y leña en Monte Alto.

También el 27, 28 y 30 de diciembre del 2010 se levantó una encuesta con 301 cuestionarios $^{(16)}$. En la gráfica I se observa que la población de estas localidades, no sólo explotó la madera y la leña, como señalaron los estudios anteriores, sino también aprovecharon las flores, los hongos (en época de lluvias), la lama y la tierra, explotando irracionalmente casi todos los recursos naturales de Monte Alto a pesar de que es un ANP. Dadas las condiciones de vida adversas, las localidades que más utilizaron estos recursos son el área de amortiguamiento de Monte Alto, Valle de Bravo, San Mateo Acatitlán y Rincón de Estradas lo que provocó la dilapidación de los recursos forestales.

Gráfico I - Número de viviendas, en las que sus habitantes han utilizado recursos forestales de Monte Alto (2010)

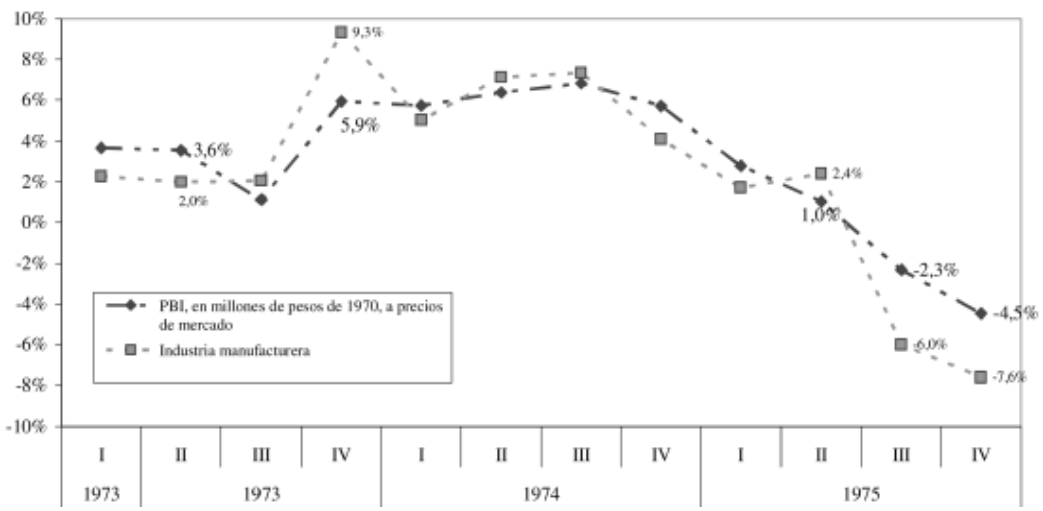

Fuente: Elaboración propia de las autoras con información de los cuestionarios aplicados en la región.

(16) De acuerdo con el cálculo de muestreo estratificado simple proporcional al tamaño de los estratos, que en el caso de la localidad de Valle de Bravo (por ser la más grande en población) se consideraron las áreas geoestadísticas básicas (AGEB's), seleccionando viviendas habitadas y en el resto de las demás localidades se consideró el total de viviendas habitadas por tener menor población. Asimismo, se calculó un n para un muestreo irrestricto aleatorio de viviendas manejando un error de estimación del $10 \%$ y un $\mathrm{P}=$ a la proporción de personas que considera que Monte Alto debe ser administrado por el Patronato ProValle de Bravo, A. C. Se calculó una muestra igual a 337 viviendas, pero como la encuesta se aplicó en las dos últimas semanas de diciembre del 2010, nada más sólo se levantó en 301 viviendas situadas en las siete localidades que rodean a Monte Alto. 
En diciembre del 2010, se conversó con los habitantes del área de amortiguamiento en Monte Alto, quienes señalaron haber escuchado casi todas las noches el ruido de las motosierras que utilizaron los infractores ambientales, quiénes llegaron a derribar hasta 5 árboles por noche. La tala clandestina es un delito ambiental relacionado con la corrupción, la falta de oportunidades económicas y la nula aplicación de leyes y normas forestales que prevengan o corrijan el problema que se ha agudizado en la región y en general en México.

\section{LA POLÍTICA Y LA NORMATIVIDAD FORESTAL EN MONTE AlTO}

\subsection{LA POLÍTICA FORESTAL}

Finalmente, las presiones y movilizaciones sociales durante los años ochenta convirtieron a la temática ambiental en un asunto público relevante y constituyeron la base de nuevos contenidos axiológicos para la sociedad ${ }^{(17)}$.

En este marco algunos de los criterios que han desarrollado los organismos internacionales para orientar las políticas ambientalistas nacionales han sido:

- La forma en que las recomendaciones en materia de medio ambiente de entidades internacionales puedan tener obligatoriedad para los Estado-nación.

- La puesta en marcha de un programa de gestión de los recursos ambientales depositándolas en manos de la sociedad civil y no del Estado.

- La idea de que los países pobres han provocado un mayor nivel de deterioro de su hábitat debido a la sobreexplotación de sus recursos.

- La organización de programas de sustentabilidad para combatir el deterioro y la pobreza en los países de menor desarrollo.

A pesar de que la política ambiental ha sido delineada por las directrices de organismos internacionales persiste la problemática forestal de muchas ANP's, como es el caso de Monte Alto. En este sentido, la CEPANAF detectó 108 asentamientos irregulares dentro del ANP, de los cuales 50 ya existían antes del decreto de 1991 y 58 se crearon entre 1991 y $1994^{(18)}$. Se ha calculado que en el 2010 quizá sean más de 180. De seguir con esta tendencia es muy probable que Monte Alto desaparezca como ANP y se convierta en un cerro repleto de construcciones y con sus adversos efectos ambientales y sociales (el disfrute de bienes privados afectan los bienes públicos): menos agua para la laguna de Valle de Bravo y oxígeno, destrucción del hábitat de la flora y fauna endémica, la eliminación de los espacios para la recreación humana y la pérdida de un importante patrimonio natural.

(17) Esta es una idea que rescatan varios autores como Beck (1996), Giddens (1996), pero para el caso de México, de la revisión que he llevado a cabo de los programas de los partidos políticos, de los programas de desarrollo de los gobiernos (de Miguel de la Madrid Hurtado y Carlos Salinas De Gortari), de los programas escolares (UNAM, UAG, UAT), que una buena parte de dicho material se tiene asociado como buen ciudadano a aquel que tiene respeto por el medio ambiente (véase misión de las universidades mencionadas, véase planes de desarrollo de Miguel de la Madrid Hurtado, Carlos Salinas de Gortari, programas políticos de PRI, PAN, PRD).

(18) Datos proporcionados por el gobierno del estado de México, Secretaría de Ecología, Comisión Estatal de Parques Naturales y de la Fauna: Ramón Arroyo Hernández, Coordinador de Planeación y Proyectos Especiales. Oficio n. SE/CEP/ DGC/CPPE/119/94. Asunto: Comentarios de la Reserva Ecológica Monte Alto. Documento de fecha 29 agosto de 1994. 
Los subproyectos referentes a la Regularización y la Administración de ANP's, impulsados por la Secretaría de Ecología del gobierno del estado de México y la SEMARNAP, permitieron que el 31 de diciembre de 1999, Monte Alto formara parte del Programa de ANP's de la entidad. Sin embargo, este programa no contempló el vínculo entre la política forestal y la economía implementadas en Valle de Bravo. Esto es evidente, cuando PROBOSQUE, SEMARNAT (Secretaría de Medio Ambiente y Recursos Naturales) y Ecología Municipal, se dedicaron a diseñar una política forestal enfocada únicamente a las acciones de reforestaciones, control de incendios y plagas, sin atender las verdaderas causas que generaron la problemática forestal en Monte Alto.

Precisamente los principios fundamentales de la aplicación de la LGEEPA y la Ley General de Desarrollo Forestal Sustentable fueron la erradicación de la pobreza y la eliminación de conductas humanas contrarias a las medidas de preservación y protección de los bosques considerados como ANP's. Sin embargo, estos principios sólo están escritos en las leyes, pero, ¿qué hay de su cumplimiento?

Lejos de resolver las deplorables condiciones de vida de las comunidades, el Estado ha contribuido a acelerar la pauperización de las mismas, mediante la inclusión de México a la economía global que destruye las formas de organización social más incipientes y precarias por no contar con las condiciones propicias que permitan insertarse exitosamente en el modelo económico. Razón por la cual, con mucha frecuencia ha minado la coherencia de las soluciones que representan sus políticas forestales, ya que el Estado ha propiciado la problemática forestal, al acelerar la pobreza de las localidades que rodean a Monte Alto que es una de las principales causas de su deterioro forestal, impidiendo con ello, la eficacia de las políticas y leyes forestales, debido a que las localidades están más preocupadas por sus condiciones de vida que por el medio ambiente que prive en Monte Alto.

\subsection{NORMATIVA FORESTAL}

A raíz de los constantes asentamientos humanos irregulares en Monte Alto se detectó una indefinición de los límites geográficos de esta ANP, porque en 1991 se contaba con 677 has de protección, ahora hay menos de 575 y, de acuerdo con los artículos 60 de la Ley General de Equilibrio Ecológico y Protección del Medio Ambiente (LGEEPA), el 10 de la Ley de Parques Estatales y Municipales del estado, y el 55 de la Ley de Protección al ambiente para el Desarrollo Sustentable del estado de México, no se puede conformar un Parque Natural Recreativo por la falta de un Plan de Manejo que detecte la vocación de esta microrregión como un parque. Además, de acuerdo con estos lineamientos jurídicos, los parques deben contar mínimamente con 1000 has de extensión y evidentemente Monte Alto no cumple con el espacio territorial para un ser un parque.

La normatividad correspondiente a las ANP's, proveniente de la LGEEPA, de la Ley de Protección al Ambiente para el Desarrollo Sostenible del Estado de México y de la Ley de Parques Estatales y Municipales del Estado de México, establece que en las ANP's no debe generarse actividad económica alguna, ni asentamientos humanos y mucho menos fomentar la tala clandestina y la práctica de incendios, a menos que en el plan de manejo 
se permita el desarrollo de alguna actividad económica bajo el concepto de desarrollo sustentable.

Asimismo, estas soluciones son ineficientes debido a que sus objetivos de preservación y protección forestales, se han traducido sólo en estadísticas sobre la reforestación, el control de incendios y plagas, la inexistente vigilancia y un nulo sistema de denuncias y sanciones.

\section{MONTE Alto y LAS ORGANIZACIONES AMbiEnTALISTAS}

El cuidado del medio ambiente es una función del Estado, sin embargo éste la desarrolla con poca eficiencia y nula eficacia porque no logra el acatamiento de la población vecina a Monte Alto para que preserve el bosque que tiene esta ANP. En este sentido, el tercer sector ha representado una alternativa para cubrir la ineficiencia e ineficacia gubernamentales en la aplicación administrativa de la política y la normativa forestales.

El 23 de mayo de 1996, las organizaciones ambientalistas que forman parte del Tercer Sector desarrollaron "El Festival de la Tierra" empezando a configurar acciones colectivas para la protección de Monte Alto. Por ejemplo, Biocenosis A. C. organizó una caminata para conocer el estado de deterioro forestal que en aquel entonces guardaba esta $\mathrm{ANP}^{(19)}$. En este recorrido participaron la CEPANAF, "Los Intocables", A. C., el Patronato ProValle de Bravo, A. C., la Asociación deportiva SANCHOP, Ciclismo de Montaña, Contacto Directo, La Unión de Propietarios de Valle de Bravo y la Dirección de Ecología Municipal. La finalidad de la caminata fue crear la conciencia entre los participantes de las OSC y el gobierno estatal y municipal del deterioro ambiental y, debido a esta acción, las instancias gubernamentales, organizaciones económicas y particulares invirtieron recursos económicos para la realización del Plan de Manejo de Monte Alto, que significó el comienzo de la búsqueda de soluciones que el tercer sector o sociedad civil implementó para limitar su problemática forestal.

Otra de las soluciones del "Festival de la Tierra" fue que organizaciones como el Patronato ProValle de Bravo, A. C., Biocenosis, A. C., la CEPANAF, la Subdirección del Zoológico de Zacango y la Coordinación del Centro Educativo del Zoológico, promovieron la creación de "Los Talleres Ecológicos para Niños", en donde se ofrecieron pláticas referentes a los ecosistemas y la fauna en peligro de extinción en Monte Alto, así como las medidas de cómo conservarlos. En total asistieron 176 niños ${ }^{(20)}$, quienes encontraron un espacio para sensibilizarse sobre el cuidado del medio ambiente y sus recursos naturales. Así, la organización del "Festival de la Tierra" significó el comienzo de las acciones colectivas

(19) Biocenosis, A. C., se hizo acreedora a dos premios, uno de ellos, fue el Mérito Nacional Forestal 1995, que fue otorgado por la SEMARNAT, por haber realizado con éxito el proyecto Jornadas de Restauración de Arroyos, y el segundo, fue otorgado en 1997, cuando el gobierno del Estado de México le entregó el premio Presea Estatal 97 a la preservación ambiental.

(20) Estos niños provinieron de escuelas ubicadas en Valle de Bravo: La Escuela de Educación Especial, El Jardín de Niños Ma. Elena Montes de Oca, La Escuela Primaria Constitución Mexicana y el Centro de Desarrollo Infantil "El Jardín de los Niños". Véase SEP, BIOCENOSIS, A. C. (del 22 al 26 de mayo de 2006). La conducción de dichas prácticas se dio con la dirección Don Leopoldo a quien sus pupilos le solicitaban "Don Polo llévenos a plantar arbolitos a Monte Alto". "Festival de la Tierra". (p. 1-2). 
para enfrentar el daño forestal que tiene Monte Alto. Esta iniciativa se prolongó al grado de seguir coordinando más talleres de este tipo, donde Biocenosis, ProValle y CEPANAF se encargaron de inculcar en los niños de varias escuelas de Valle de Bravo las ideas de preservación de los recursos naturales y la fauna del bosque de Monte Alto.

Durante las décadas de los noventa y la primera del nuevo milenio, las OSC como Biocenosis, los Intocables, FOVASO y ProValle de Bravo se enfocaron a la restauración de suelos, reforestación y prevención de incendios, con acciones como la creación de brechas corta fuego, además del impulso de la agricultura orgánica y, en el trabajo de promotores ambientalistas dedicados a impulsar la educación ambiental informal en niños y jóvenes. Esto se ha llevado a cabo, con convocatorias a escuelas primarias y secundarias además de personas interesadas en la preservación del ANP de Monte Alto. Con esas acciones se logró el diseño del plan de actividades que ha permitido la distribución y asignación de actividades entre los participantes.

Por otra parte, se programaron visitas a Monte Alto en las que participaron niños de $4^{\circ}$ a $6^{\circ}$ grado de primaria para realizar prácticas de reforestación y de construcción de brechas corta fuego. De esta manera, se difundieron conocimientos que generaron cambios en la forma de aprovechar los recursos naturales, puesto que se aportaron ideas de cómo cuidar el bosque. A largo plazo se ha generado la esperanza de disminuir la tala clandestina y el aprovechamiento desmedido de los recursos forestales no maderables.

Aparte de realizar acciones que contribuyeron directamente a disminuir el deterioro forestal de Monte Alto, también las organizaciones ambientalistas se preocuparon por aspectos socioeconómicos de la población Vallesana. El Patronato ProValle creó un dispensario médico donde se procuró el servicio de salud a la población de escasos recursos mediante consultas y surtido de medicamentos totalmente gratuitos o a precios simbólicos, además de la rehabilitación de personas con capacidades diferentes.

En el 2006 con el objetivo de apoyar a las comunidades, Biocenosis A. C. impartió en el Centro Bio-Regional ${ }^{(21)}$ talleres de capacitación de desarrollo comunitario, en lugares como la granja orgánica "La Madriguera", ubicada en la Loma de Chihuahua y Valle de Bravo, donde se desarrollaron cursos para ir "Descubriendo la Naturaleza" (22), dirigido a los niños y maestros de los Álamos y Loma de Chihuahua. También se impartieron talleres de verano de "Manejo Comunitario de Microcuencas", dirigidos a estudiantes, personas dedicadas a la actividad agropecuaria, profesionistas y público en general. Este grupo

(21) En 1998, aun cuando sus labores comenzaron en 2002, se formó el equipo de Biocenosis, A. C. con el Centro Bio-Regional Valle de Bravo, con la intención de limitar el creciente deterioro ambiental de la cuenca, el cual está conformado por las organizaciones ambientalistas, Biocenosis, A. C., el Promotor Ambiental, el Sr. Leopoldo Valdez, "Los Intocables", A. C. el Patronato Pro-Valle de Bravo, A. C., el dispensario Tonantzin, el Centro de Rehabilitación promovido por FOVASO, A. C., la Asociación de Parques Ecológicos de Valle de Bravo, A. C., y una biblioteca que da servicio de consulta sobre materiales referente al medio ambiente y la ecología de Valle de Bravo, entre otro tipo de información. Los objetivos que contemplaba este Centro Bio-Regional Valle de Bravo eran constituirse como un espacio de coordinación e investigación sobre el agua y la biodiversidad; impulsar la comunicación y la capacitación sobre la cuenca; promover la planificación y el desarrollo de políticas coherentes con la restauración y el manejo adecuado del patrimonio natural de la cuenca; hacer del dominio público la situación de constante deterioro ambiental y ecológico de la zona; restablecer una cultura que signifique cuidado y amor hacia la naturaleza, lo cual implica pleno conocimiento de ella. Asimismo, detectar y frenar los factores que alteran el medio ambiente y sus recursos naturales, en la Cuenca.

(22) Este curso fue impartido por la Lic. Gabriela Polanco, en mayo del 2005. 
intercambió ideas sobre técnicas y prácticas de restauración de suelos y ríos, producción agrícola orgánica, fabricación de ecotecnias (lavaderos, letrinas secas, regaderas solares, separación de desechos, elaboración de composta y piletas, entre otros temas).

Asimismo, se organizaron talleres dirigidos a mujeres de las comunidades rurales de la microcuenca de "El Crustel" en Monte Alto, donde se les sensibilizó sobre su papel en el mejoramiento de sus comunidades al proporcionarles conocimientos para la aplicación en su quehacer cotidiano, como es el caso del ahorro del agua, manejo de la agricultura orgánica (libre de fertilizantes y otras sustancias químicas) y la preservación de ríos, lagunas y suelos.

Biocenosis también impartió el taller de "Manejo Integral de Microcuencas" en el que la Coordinación de Programas Regionales de la SEMARNAT seleccionó a 20 personas de la zona rural del Distrito Federal, para desarrollar proyectos de liderazgo en la preservación de recursos naturales, las cuales provenían de localidades como Cuajimalpa, el Desierto de los Leones, Tlalpan, Milpa Alta, Tláhuac, Viveros de Coyoacán y Sierra Guadalupe. Por su parte, SEMARNAT y el Centro de Información y Comunicación Ambiental de Norte América (CICEANA) participaron en la organización de esta capacitación sobre el manejo racional de recursos naturales. Con ello se generó la comunicación abierta entre el gobierno y la sociedad civil y los individuos aprendieron a socializarse sus experiencias y formular diseños de enfoques, métodos y perspectivas para superar las ineficiencias institucionales en materia de desarrollo comunitario.

Por su parte, el Fondo Valle de Bravo Solidaridad (FOVASO) se enfocó a la educación y capacitación formal con el objetivo de ofrecer alternativas de desarrollo social productivo para la población desprotegida de Valle de Bravo y municipios vecinos. Para ello creo centros operativos de Rehabilitación Física (que desarrolló junto con el Patronato ProValle de Bravo), de Formación Mazahua y de Formación y Capacitación "Jóvenes por el Cambio". Todos los individuos que fueron albergados en dichos centros fueron capacitados en alguna labor y con ello se evitó la drogadicción, el pandillerismo o la migración hacia los Estados Unidos. Además de que desarrollaron prácticas de preservación y protección forestal en el laboratorio denominado Monte Alto.

En cuanto al desarrollo productivo, el Centro de Capacitación "Jóvenes por el Cambio" promovió la formación de líderes comunitarios para la creación de microempresas, con lo cual se generó autoempleo y se impulsaron algunas actividades económicas. Asimismo, en ese Centro se asesoraron a personas y familias para que realizaran labores agrícolas, agroindustriales, forestales, ganaderas, entre otro tipo de actividades, que no sólo lograron la mejoría de las condiciones de vida de las comunidades vallesanas, sino también implementaron el desarrollo sustentable.

De igual forma, en 1999 "Los Intocables" publicaron el "ABC de la Ecología", cuyo objetivo fue crear la conciencia sobre la problemática ambiental de Monte Alto y con ello llevar a cabo acciones para promover la participación social y disminuir esta problemática. "Los Intocables" asistieron a las escuelas para trabajar con niños sobre cómo mantener limpia la escuela, el uso racional de los recursos naturales y la enseñanza del contenido de su obra. De este modo, siguieron visitando varias escuelas, haciendo labor de concientización, que implicó una ardua dedicación por ser una actividad de desarrollo social. 
Por su parte, Biocenosis, A. C. ProValle y FOVASO adquirieron el carácter de organizaciones ambientalistas al propiciar un cambio en el uso y manejo racional de los recursos naturales Leff (1998, p. 96) e implementar mejoras en las condiciones de vida de las comunidades vecinas. El ambientalismo promovido por estas organizaciones planteaba la búsqueda de soluciones productivas que integraran el medio ambiente y las necesidades sociales. De manera conjunta, estas organizaciones elaboraron el Plan de Manejo de Monte Alto en 1995 cuyo seguimiento fue plasmando en el Plan de Manejo Forestal 2005, el cual propone la zonificación en materia de protección, restauración y conservación forestal, amortiguamiento, circuitos interpretativos y proyectos productivos para alejar a la población de la depredación de los recursos forestales maderables y no maderables:

En el caso del segundo plan, se organizaron las "Jornadas por Monte Alto" (mapa 2). Las organizaciones ambientalistas, con la participación del gobierno municipal de Valle de Bravo, la Secretaría de Ecología del gobierno del estado de México, la CEPANAF, la SEMARNAT, organizaciones locales, la Secretaría de Educación Pública, PROBOSQUE, Secretaría de Desarrollo Agropecuario (SEDAGRO) y la comunidad para desarrollar reuniones de trabajo bajo la dirección de Servicios Públicos Municipales y Ecología. Esos planes consistieron en hacer recorridos en la zona y definir equipos de trabajo y técnicas de restauración de suelos y reforestación en la cima de Monte Alto y el área del arroyo "Chiquito". La restauración del suelo de Monte Alto se realizó mediante la construcción de canales de desvío, tinas ciegas, cercados, retenes de piedra o matorral, arropes de paja, ocojal, recortes de jardín y reforestaciones de pino y encino.

Mapa 2. Sitios de Trabajo de las Jornadas de Monte Alto

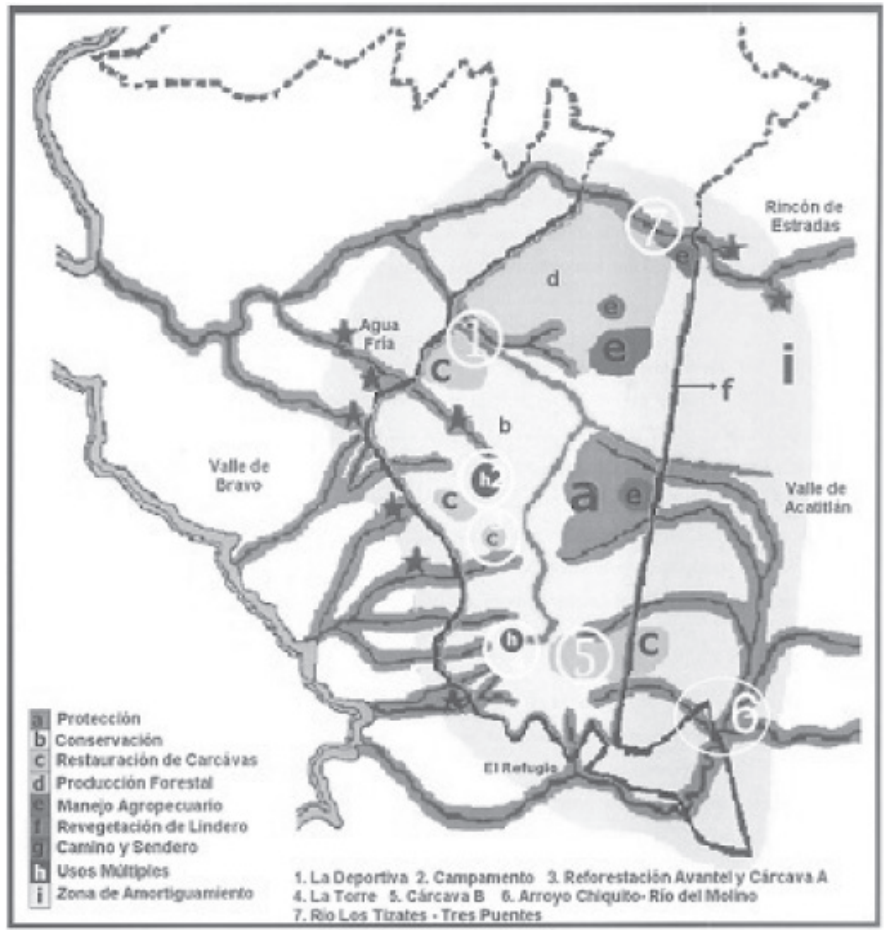

Fuente Biocenosis, A. C. (mayo 2001). Plan de Manejo para Monte Alto, Valle de Bravo, Estado de México, México, p. 17. 
Estas acciones tenían el objetivo de limitar el deterioro forestal de esta ANP para lo cual se creó en 1996 la Asociación de Parques Ecológicos de Valle de Bravo, A. C. lo que significó una coordinación más efectiva para promover el cuidado y la preservación de las ANP's a nivel nacional, además del impulso a la cultura, las bellas artes, las artes populares y el desarrollo comunitario de Valle de Bravo.

A pesar de los objetivos comunes de las organizaciones ambientalistas (ver cuadro III) enfrentaron conflictos entre ellas, debido a que manejan diferentes metodologías para resolver los problemas forestales de la región, lo que en ocasiones han impedido llegar a acuerdos entre ellas para trabajar conjuntamente y lograr mejores resultados. Por ello, desarrollaron iniciativas por separado para mejorar las condiciones forestales existentes en el ANP. Tal es el caso de Biocenosis, A. C. que es la organización que más trabajó en la zona aunque en ocasiones se veían limitados por la falta de recursos para promover la reforestación y la restauración de suelos de esta ANP. El liderazgo que asumió esta organización en los planes de manejo de Monte Alto fue muy importante, no obstante que a veces no contaron con el apoyo de los "Intocables" o incluso de ProValle por el hecho de que se tomaron decisiones arbitrariamente sin tomar en cuenta a las demás organizaciones ambientalistas que también querían sumarse al esfuerzo de la planeación.

\section{Cuadro III - Objetivos de las organizaciones} ambientalistas en Valle de Bravo en el año 2005

\begin{tabular}{|c|c|c|}
\hline Año & Objetivos & Escritura pública \\
\hline \multicolumn{3}{|c|}{ El Patronato Pro Valle de Bravo, A. C. } \\
\hline 1984 & $\begin{array}{l}\text { 1) Fomentar, proteger, conservar y planificar el medio ambiente de Valle de Bravo con la } \\
\text { finalidad de fomentar la conservación del equilibrio ecológico de la Presa, de las áreas na- } \\
\text { turales protegidas y de la salud de las personas de escasos recursos. }\end{array}$ & $\begin{array}{l}17,223 \text {, de fecha } \\
19 \text { de noviembre } \\
\text { de } 1989\end{array}$ \\
\hline \multicolumn{3}{|c|}{ La Asociación de Parques Ecológicos de Valle de Bravo A. C. } \\
\hline 1996 & $\begin{array}{l}\text { 1) Mantener y conservas las áreas naturales protegidas, abarcando bosques, parques, ríos } \\
\text { y lagos. } \\
\text { 2) Recibir donativos, préstamos o cualquier otro tipo de bienes o servicios de personas físicas } \\
\text { o morales, lucrativas o no lucrativas, públicas o privadas, mexicanas o extranjeras, para el } \\
\text { cumplimiento de sus objetivos y metas. } \\
\text { 3) Promover el cuidado y la preservación de las ANP a nivel nacional e internacional, im- } \\
\text { pulsando la cultura, las bellas artes y las artes populares de Valle de Bravo. }\end{array}$ & $\begin{array}{l}12,474, \text { de fecha } \\
16 \text { de octubre de } \\
1996\end{array}$ \\
\hline \multicolumn{3}{|c|}{ Biocenosis, A. C. } \\
\hline 1989 & $\begin{array}{l}\text { 1) Investigar y restaurar las zonas aledañas a los ríos. } \\
\text { 2) Restaurar y proteger las ANP. } \\
\text { 3) Impulsar la producción orgánica, el desarrollo urbano y la comunicación. } \\
\text { 4) Realizar planes y programas de manejo de bosques. } \\
\text { 5) Promover el ordenamiento ambiental de la Cuenca de Valle de Bravo. }\end{array}$ & $\begin{array}{l}\text { 18,744, de fecha } 7 \\
\text { de febrero de } 1983\end{array}$ \\
\hline \multicolumn{3}{|c|}{ El Fondo Valle de Bravo Solidaridad, A. C. } \\
\hline 1991 & $\begin{array}{l}\text { 1) Ofrecer alternativas de desarrollo social productivo para la población desprotegida de } \\
\text { Valle de Bravo y municipios vecinos, mediante la constitución de sus centros operativos: } \\
\text { Centro de Fomación Mazahua, Centro de Formación y Capacitación "Jóvenes por el cambio", } \\
\text { Centro de Rehabilitación Física y Centro de Desarrollo Indígena. } \\
\text { Esta organización no es ambientalista pero ha contribuido constantemente a las labores de } \\
\text { preservación y protección de los recursos forestales mediante la educación y la formación } \\
\text { de una conciencia ambientalista canalizando a su gente en labores de reforestación y control de } \\
\text { incendios de diversas ANP en Valle de Bravo. }\end{array}$ & $\begin{array}{l}1,360 \text {, de fecha } 13 \\
\text { de febrero de } 1991\end{array}$ \\
\hline
\end{tabular}




\begin{tabular}{|l|l|l|}
\hline \multicolumn{3}{|c|}{ Los Intocables, A. C. } \\
\hline 1993 & $\begin{array}{l}\text { 1) Realizar labores de limpieza, reforestación y apertura de brechas corta fuego en las ANP. } \\
\text { 2) Impartir educación ambiental mediante la implementación de cursos, seminarios y con- } \\
\text { ferencias. Combatir los incendios forestales. } \\
\text { 3) Crear conciencia sobre la problemática ambiental y realizar acciones para promover la } \\
\text { participación social. }\end{array}$ & $\begin{array}{l}\text { Datos no } \\
\text { Elibles }\end{array}$ \\
\hline \multicolumn{3}{|c|}{ El Promotor Ambientalista, Sr. Leopoldo Valdez Cruz } \\
\hline 1991 & $\begin{array}{l}\text { Capacitar y promover entre los niños y jóvenes los conocimientos sobre reforestación, } \\
\text { restauración de suelos y brechas corta fuego. }\end{array}$ & $\begin{array}{l}\text { Datos no } \\
\text { disponibles }\end{array}$ \\
\hline
\end{tabular}

Fuente: elaboración propia con datos obtenidos de los cuestionarios aplicados a estas organizaciones.

En 2010 se aplicó una encuesta a la población de Monte Alto sobre el desarrollo de las actividades de las organizaciones ambientalistas. En los resultados los habitantes señalaron que Biocenosis A. C. no era la organización ambientalista preferida por esta población para que siguiera con la gestión del ANP, debido a la falta de transparencia en las transferencias públicas y privadas, aunque fue una de las organizaciones más productiva en materia de preservación y protección de la Cuenca de Valle de Bravo.

En el caso de FOVASO hubo aprovechamiento de recursos provenientes del delito de peculado que cometió Lic. Óscar Espinosa Villarreal, quien fue regente de la ciudad de México de 1994 a 1997. Según la Procuraduría General de la República (PGR), este funcionario utilizó 45 millones de dólares para uso personal, y una parte se lo donó a su madre, quien era la Directora de FOVASO. Pero, finalmente en agosto del 2001, se logró su extradición ${ }^{(23)}$. Curiosamente en 2001 el Centro de Capacitación "Jóvenes por el Cambio de FOVASO" dejó de trabajar como organización civil. Lo sorprendente es que los gastos en que incurrió esta organización no eran pequeños ¿cuál habrá sido entonces la principal fuente de financiamiento de FOVASO? Surge esta interrogante debido a que esta organización tuvo que cubrir los sueldos de 29 profesores y administradores, además de los gastos generados por albergar estudiantes, quienes no pagaron ninguna cuota (por ser población en condiciones de pobreza extrema), más la compra de materiales de trabajo y el equipamiento de los tres centros que conformaban a FOVASO.

Por otro lado, las organizaciones ambientalistas que desarrollaron proyectos de agricultura orgánica, elaboración de ecotecnias, aprovechamiento productivo y sustentable de los recursos naturales, se constituyeron más que en agentes de un cambio social en una fuente complementaria de obtención de ingresos no agropecuarios. En este sentido, las organizaciones ambientalistas no fueron agencias que promovieran el desarrollo local de las comunidades, sino que contribuyeron a desplegar algunos proyectos que no tienen un alto impacto en la mejora de las condiciones de vida de la población.

Para institucionalizar el proceso de creación y reforzamiento de las OSC u organizaciones ambientalistas en 2004 el Gobierno Federal creó la Ley de Fomento a las Actividades realizadas por las Organizaciones de la Sociedad Civil que reconoce una serie de derechos y obligaciones de las organizaciones ambientalistas, las cuales se crean para velar por el derecho que tiene todo mexicano de gozar de un medio ambiente sano y equilibrado

(23) Su esposa, María de los Angeles Mijares y sus tres hijos regresaron de Managua el 7 de agosto del 2001, para esperar la repatriación de este exfuncionario, quien a su regreso quedó libre y contó con tres días para presentarse ante el juez que llevaba su caso. Véase periódico El Financiero. (Jueves, 9 de agosto del 2001). Sociedad, (p. 42). 
para su desarrollo y bienestar social. Estas organizaciones tienen el derecho de recibir transferencias gubernamentales, de empresas y particulares y como obligación aplicar estos recursos para el objetivo social para el cual fueron creadas, aunado a su respectiva rendición de cuentas.

Asimismo, al considerar los resultados de la encuesta realizada a los habitantes de las siete localidades (gráfica II), las organizaciones que fueron reconocidas por la labor que realizaron en el medio ambiente al promover la participación de las personas de estas localidades en los trabajos de preservación y protección forestal en Monte Alto fueron: FOVASO, el Patronato ProValle de Bravo y el Promotor Ambientalista, Sr. Leopoldo Valdez Cruz, y en menor escala Biocenosis y "Los Intocables".

\section{Gráfico II - Número de viviendas que dijeron conocer a la organización ambientalista a partir de su desempeño en la localidad (2010)}

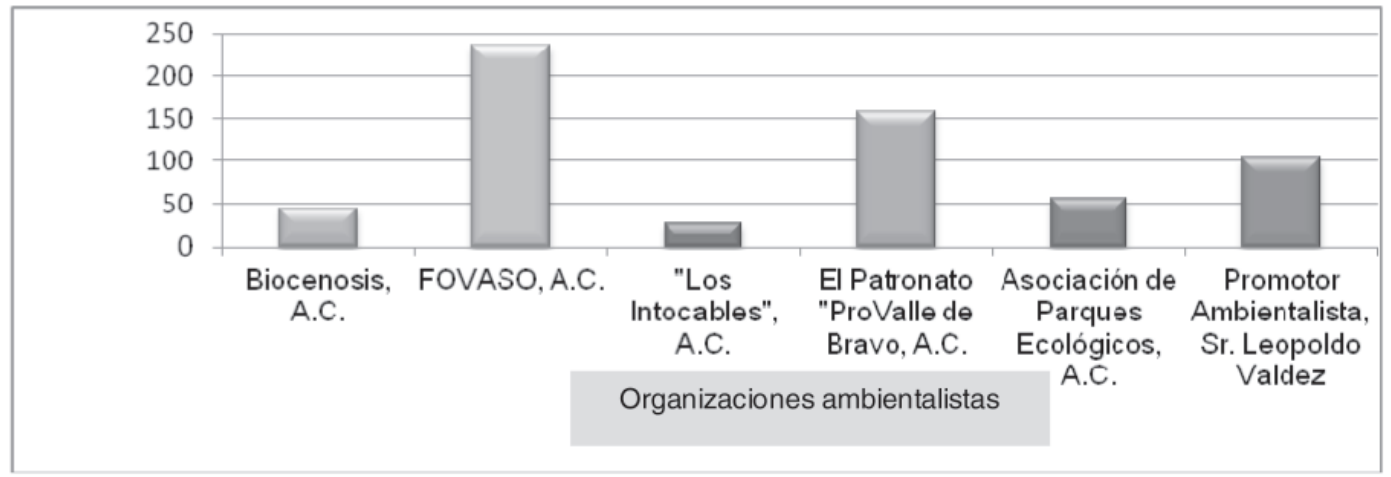

Fuente: Elaboración de las autoras con información de los cuestionarios aplicados a las las viviendas encuestadas en las localidades dela región.

De igual forma, el $87 \%$ del total de las personas encuestadas en las localidades cercanas al ANP, consideró adecuado que Monte Alto fuese un Parque Natural Recreativo (gráfico III) debido a que la importancia de Valle de Bravo como un espacio para fomentar el deporte y la recreación. Ahora, lo imperioso es incluir a un mayor número de personas de estas localidades en las labores de conservación. Desde esta perspectiva, las organizaciones ambientalistas jugaron un papel muy importante ya que construyeron vínculos para promover la acción colectiva en la aplicación de las medidas que señalan las leyes y políticas forestales que ha diseñado el gobierno para proteger los recursos forestales.

A pesar de que las organizaciones ambientalistas tuvieron sus diferencias en cuanto a sus objetivos (cuadro II) al trabajar en conjunto se mostraron flexibles y comprensivas lo cual impidió la burocratización de sus acciones pues constantemente buscaron alternativas para solucionar el problema de la deforestación en Monte Alto. Por ello las organizaciones ambientalistas, aún con sus propias diferencias y dificultades para articularse actuaron en el "aquí y ahora" como acción colectiva, impulsaron iniciativas ambientalistas que desafían la política forestal ya que ponen en evidencia las ineficiencias e ineficacias de la estructura administrativa del Estado - organismo que incurre en injusticias al no cumplir con la misión para la cual fue creada, provocando con ello, la falta de servicios ambientales y deteriorando las condiciones de vida de las localidades cercanas a Monte 
Alto. Esta situación suscitó que las organizaciones ambientalistas se solidarizarán entre ellas conformando la Asociación de Parques Ecológicos de Valle de Bravo, A. C. para erradicar la problemática forestal.

Gráfico III - Porcentaje de viviendas que consideran adecuado que Monte Alto sea un Parque Natural Recreativo (2010)

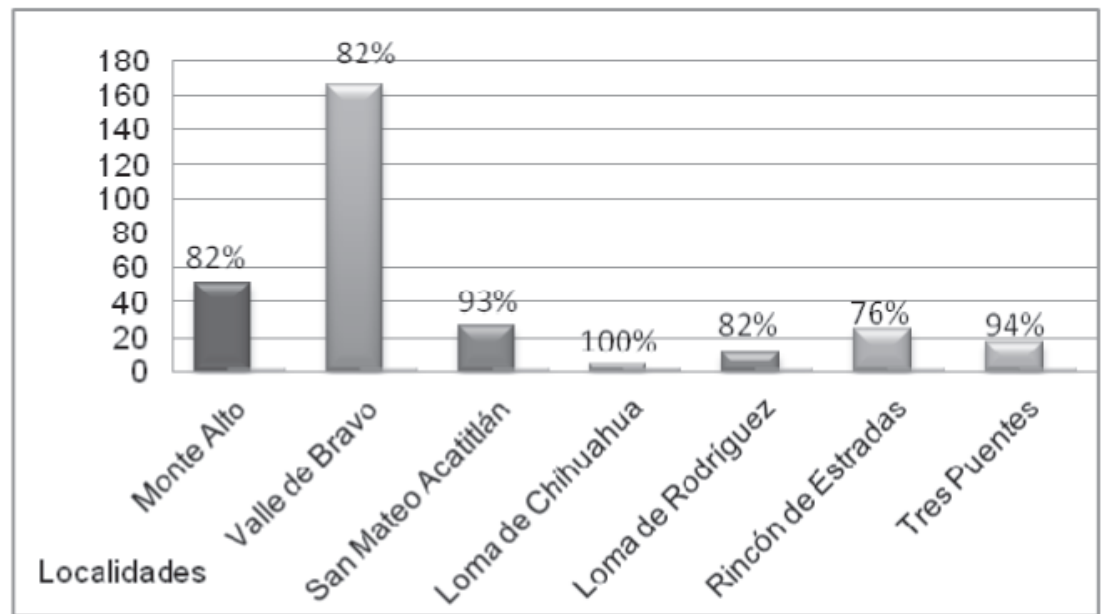

Fuente: Elaborado por las autoras con información de los cuestionarios aplicados a las viviendas encuestadas en las localidades de la región.

Por añadidura, desde abril de 1999 las organizaciones ambientalistas publicaron artículos de divulgación en la revista "el Canto de la Cúa" ${ }^{(24)}$ referentes a la problemática ambiental de la Cuenca de Valle de Bravo y las acciones para contrarrestarla. El objetivo de tal publicación fue crear conciencia sobre la problemática ambiental que vive en la actualidad esta cuenca; así como también llevar a cabo proyecciones de cine comunitario e impresión de una variedad importante de folletos que promovieron la conservación y protección del medio ambiente y sus recursos naturales en Valle de Bravo.

Una de las limitantes que tuvo el quehacer de las organizaciones ambientalistas fue siempre la falta de recursos para desarrollar sus actividades ambientalistas. Ante esto, Asimismo, para promover la participación de diversas instituciones que contribuyan con recursos monetarios, materiales, humanos y técnicos, necesarios para establecer la agenda de trabajo que requiere la preservación del ANP de Monte Alto, se estableció en el 2001, un Comité Organizador Interinstitucional especial para la gestión de Monte Alto ${ }^{(25)}$, que ha estado conformado por todas aquellas instituciones que son responsables del medio ambiente y sus recursos naturales; junto con la participación de las escuelas y voluntarios, que será impulsada mediante intensas campañas de difusión y promoción dirigidas a la

(24) Existen en la actualidad, ocho publicaciones del "Canto de la Cúa", las cuales analizan temas como "Monte Alto, lugar de depredación" (año 1, número 1, julio de 2010); otros temas como "Necesaria la participación social en el ordenamiento ecológico de Valle de Bravo"; "Acuerdos y diferencias entre organizaciones de Valle de Bravo y el gobierno; "El crecimiento de Valle de Bravo a costa de su patrimonio natural", entre otros más.

(25) Un ejemplo de ello, lo constituyó el conjunto de apoyos que se dieron entre las organizaciones ambientalistas, la CEPANAF, la Secretaría de Educación Básica, PROBOSQUE, SEMARNAT y la población en general, para desarrollar la restauración de suelos y reforestación de Monte Alto, en junio y julio del 2001. 
población, realizadas por las organizaciones ambientalistas. Esta forma de cooperación sería idónea porque los recursos económicos se aplicarían más eficientemente, ya que habría varios interesados en resolver verdaderamente la problemática forestal de Monte Alto, ya que estarían cooperando, no sólo económicamente, sino también participando en las labores de conservación. De esta manera, en septiembre del 2001, se firmó un Contrato de Fideicomiso de Inversión y Administración, constituido entre la Secretaría de Ecología (gobierno del estado de México), el gobierno municipal de Valle de Bravo y el Patronato ProValle de Bravo, A. C., en el que cada uno de estos miembros ha invertido $\$ 50,000.00$ para preservar el patrimonio natural que constituye Monte Alto. Aunque en este fideicomiso estaría haciendo falta la participación de las comunidades, ya no digamos como inversionistas, debido a que carecen de las condiciones materiales para participar de esta manera, pero sí sería importante, su inclusión en los empleos que se generen y en el proceso de comunicación que promovería, sobre todo, el patronato en las actividades propias de la conformación de un parque natural recreativo (Cárcamo, 2006).

\section{REFLEXIONES FINALES}

El análisis de las acciones colectivas en Monte Alto, es un ejemplo más de su papel en la formulación de políticas públicas. Las continuas movilizaciones de protesta de las OSC en la localidad hicieron evidentes los problemas de la región y la necesidad del diseño de una política ambiental en la región.

Los diversos riesgos ambientales, que han hecho que la comunidad de Monte Alto, atienda de manera continua estos problemas ha llevado a plantear una reafirmación de las acciones del Estado, tales como:

a) Reuniones en la comunidad.

b) Formulación de un plan local para el manejo de recursos forestales.

c) Reforestación y medidas de protección (contra incendios, plagas y enfermedades arbóreas) y proyectos de educación.

d) Proyectos de desarrollo sustentable alternativos a la explotación maderera y que llevaron a la creación de empleos en la región.

e) Inversiones en asociaciones público-privadas para la conservación y recuperación de la zona.

f) Educación y capacitación regional.

g) Vínculo política ambiental con política económica (modelo Neoliberal Globalización).

Los diversos intereses en la región, hace que las políticas forestales en el ANP de Monte Alto presente una compleja y conflictiva relación en la comunidad. El tema forestal es uno de los principales problemas que presenta el Estado de México y esto se debe a varios factores conjugados: división en la administración de los recursos forestales por parte de la comunidad, la existencia de agentes externos (nuevos propietarios asentados irregularmente, intereses privados con la tala inmoderada, luchas entre diversos intereses económicos) y el enfrentamiento entre la comunidad y autoridades locales. 
Derivado de las ineficiencias de las leyes y políticas forestales aplicadas en el ANP de Monte Alto la acción colectiva permitió el desarrollo de un conjunto de estrategias para generar conciencia sobre los daños y el peligro que implicaron dichas ineficiencias. Debido a ello, emergieron en los años ochenta y noventa algunas organizaciones ambientalistas quienes pusieron freno a estas políticas a través de acciones colectivas enfocadas a desarrollar proyectos de preservación y protección de la riqueza forestal de Monte Alto, lo cual significó un proceso de aprendizaje entre las instancias gubernamentales dedicadas a la protección del medio ambiente, las comunidades vecinas y los diversos visitantes de esta ANP.

Las acciones colectivas, que representa un conjunto de formas de comunicación abierta, obedece a un factor común: la convicción de justicia de las organizaciones ambientalistas y de la comunidad. Con ello, es posible defender el derecho de los individuos al acceso y cuidado de un bien común como lo es un medio ambiente sano y equilibrado y el aprovechamiento racional de los recursos naturales, para el desarrollo de toda forma de vida y de las posibilidades productivas del país. Esta idea de justicia está plasmada en el artículo cuarto de las Garantías Individuales y el artículo 25 de la Constitución Política de los Estados Unidos Mexicanos, además de los artículos 1을 (fracción I) y 15 (fracciones I, XII y XIII) de la LGEEPA.

Las acciones colectivas en Valle de Bravo han adquirido la característica de una política de influencia, que en 2010 fue representada por los conocimientos, experiencias y tradiciones compartidas socialmente, cuyos contenidos se encontraron en los planes de manejo de Monte Alto; en el proyecto para la implementación de un parque natural recreativo autosustentable en Monte Alto; en la puesta en marcha de los cursos-taller, que promovieron el manejo sostenible de los recursos naturales; en los programas de restauración de suelos y reforestación, denominados "Jornadas por Monte Alto"; en el proyecto Cimas y Cañadas; en los programas de comunicación, por medio de radio, prensa y publicaciones, y recientemente, su participación en el Plan de Ordenamiento de la Cuenca de Valle de Bravo (organizado por Probosque, gobierno de Valle de Bravo y SEMARNAT, concretamente con la Propuesta Técnica para incluir la Participación Social en la elaboración de este Ordenamiento Ecológico de Valle de Bravo.

La unión de esfuerzos entre instituciones de la sociedad civil y el gobierno, que antes era impensable su vinculación porque se mantenía la idea de que sus ideologías eran totalmente disociadas, pero ahora que los problemas socioambientales han llegado a su punto álgido, no sólo en América Latina, sino en el mundo entero, convergen para solucionar realmente una problemática forestal que afecta de manera directa al equilibrio ambiental no sólo de Valle de Bravo, sino de otras poblaciones. La gravedad de la problemática forestal hizo posible la movilización social de varios actores con un objetivo común que era el recuperar forestalmente a Monte Alto, que desde principios del siglo XX era como el "monte selvoso", que envolvía con singular belleza al valle fértil, regado por todos los ríos que bajaban de este hermoso cerro redondeado ${ }^{(26)}$.

(26) Joaquín Arcadio Pagaza, famoso poeta vallesano escribió en 1905 unos poemas acerca de Monte Alto, en ellos, se describe la belleza natural que en aquel entonces predominaba en este zona de Valle de Bravo y constituyen quizá la única evidencia de cómo era antes este hermoso lugar. Véase Biocenosis, A. C. (1997). Plan de Manejo de Monte Alto. 
Este caso de estudio es un ejemplo de una microrregión que comparte con otros países de América Latina y el mundo los efectos negativos de la globalización, pero que replantea al mismo tiempo sus posibles soluciones.

Sin embargo una de las principales limitantes de este estudio es que la sociedad civil representada en este caso por las organizaciones ambientalistas se ve afectada por la existencia de conflictos e intereses económicos y políticos que tienen los gobiernos federales, estatales y locales en torno al medio ambiente (Mattar and Reis, 2010) que impiden que las organizaciones ambientalistas puedan emprender acciones que limiten con firmeza el deterioro forestal de Monte Alto. En el caso particular de los asentamientos humanos irregulares en esta ANP, podemos ver que hay casas residenciales en la parte alta de Monte Alto, cuya principal vista es la laguna de Valle de Bravo. Si históricamente el gobierno en sus tres niveles no ha podido frenar esta problemática, entonces las labores de reforestación y protección del medio ambiente son imposibilitadas por la falta de eficacia gubernamental para frenar estos asentamientos. Además en el caso de la tala clandestina que se realiza a altas horas de la noche en esta ANP, no hay ningún control de este problema, debido a que falta la vigilancia nocturna, que impida la delincuencia de infractores ambientales, pero la principal causa de este último problema, entre otros, es que la política forestal no está vinculada con la política económica que asegure la inclusión de las personas que viven en condiciones de rezago social, además de reforzar administrativamente las acciones de la PROFEPA que limite la delincuencia ambiental y la corrupción. Razón por la cual la participación y rol de la sociedad civil en la arena ambiental requiere de fomentar más la investigación y la elaboración de propuestas, ya que la problemática del medio ambiente impide aplicar primero, el concepto de desarrollo sustentable (elaborado por Gro Brundtland en "Nuestro Futuro Común" de 1987) y segundo está en la agenda de la Organización de las Naciones Unidas como una prioridad en la búsqueda de soluciones.

Agradecimiento a la Maestra Alexandra Marissa Cano Mosqueda (Catedrática de la Universidad de Guanajuato, Campus Irapuato, México) por su valioso apoyo en la traducción en inglés del resumen de este trabajo.

\section{REFERÊNCIAS BIBLIOGRÁFICAS}

BECK, Ulrich; Giddens Anthony; Lash, Scott. Modernización Reflexiva. Política, Tradición y Estética en el Orden Social Moderno. Madrid: Alianza Editorial, 1996. p. 261-265.

BIOCENOSIS, A. C. (1997). Plan de Manejo de Monte Alto. Valle de Bravo, Estado de México, México. BIZBERG, Ian. El papel de la sociedad civil en las transformaciones políticas actuales. En: VEGA CANOVAS, Gustavo. México, los retos ante el futuro. México: El Colegio de México, Fondation Konrad Adenauer, p. 1-31, 2007 disponible en: <http://cei.colmex.mx/PDFs/Prof\%20Bizberg/el\%20 papel\%20de\%20la\%20sociedad\%20civil.pdf> Acceso en: 23 feb. 2010.

CÁRCAMO Solís, María de Lourdes. La problemática forestal de Monte Alto, Valle de Bravo (1994-2004), un caso de reconstrucción de la sociedad civil. México: tesis doctoral, Universidad Iberoamericana, A. C., p. 1-241, 2006.

COHEN Jean L. y ARATO, Andrew. Civil Society and Political Theory. Cambridge, Massachusetts: The MIT Press, 1995.

CONAPO. Disponible en: <http://www.conapo.gob.mx/es/CONAPO/Indices_de_Marginacion> Acceso en: 27 dic. 2012. 
CONEVAL. Disponible en: <http://web.coneval.gob.mx/Paginas/principal.aspx\#.UQL7BWdWLDo> Acceso: 27 dic. 2012.

ESCUDERO, Edmond Frederic Grieger. Las Acciones Colectivas en el ámbito del Derecho Ambiental. Centro de Estudios Jurídicos y Ambientales. Revista Derecho Ambiental y Ecología, México, n. 38, año 7, ago./sep. 2010.

FINANCIERO, El (Periódico). Sección Sociedad, p. 42, jueves 9 de agosto de 2001.

GIDDENS, A. Las consecuencias perversas de la modernidad. Fundación Dialnet, p. 33-72, 1996. HABERMAS, Jürgen, Pensamiento postmetafisico, versión castellana de Manuel Redondo, México, D.F: Taurus Humanidades, 1990.

INEGI. Anuarios estadísticos y censos de población y vivienda. México, 1995, 2005 y 2010.

LARSON, Jorge y SARUKÁN, José. Cuando los bienes comunes son menos trágicos: dominios eminentes y privilegios comerciales en la valoración patrimonial del medio rural. INE, SEMARNAT Gaceta Ecológica, México, n. 67, p. 7-27, abril-junio 2003.

LEFF, Enrique. El Saber Ambiental: Sustentabilidad, racionalidad, complejidad, poder. México: Editorial siglo XXI, 1998. p. 1-276.

LÓPEZ Maya, Margarita y LANDER, Luis E. Novedades y continuidades de la protesta social en Venezuela. Revista Venezolana de Economía y Ciencia Social, Venezuela, Universidad Central de Venezuela, vol. 12, n. 1, ene./abr. 2006.

MATTAR, Luciano and REIS, Bruno P. W. Collective Action and Agent-Based Models: Adding Diversity to a Rational Choise Model. Brazil: Second Brazilian Worshop on Social Simulation, 2010. p. 41-46.

MERLINSKY, Gabriela. La gramática de la acción colectiva ambiental en Argentina: reflexiones en torno al movimiento ciudadano ambiental de Gualeguaychú y su inscripción en el espacio público. Revista Temas y debates, Argentina, Facultad de Ciencias Políticas y Relaciones Internacionales. n. 15, p. 35-60, 2008.

OLSON Marcur. La lógica de la acción colectiva. México: Limusa, 1999. p. 1-147.

RUIZ, Arminda. El perfil de la protesta ambientalista: Estudio de la acción colectiva conflictiva en la década de los noventa en el Estado de México. Sociedad Latinoamericana, 2011. Recuperado en: $<$ http://sociedadlatinoamericana.bligoo.com/el-perfil-de-la-protesta-ambientalista-en-la-decada-de-estado-de-mexico> Acceso en: 23 oct. 2012.

SEDAGRO, Romano. La sustentabilidad como alternativa social. Disponible: <http://www.uaemex. mx/plin/psus/rev6/e04.html> Acceso en: 17 abr. 2006.

SEMARNAT. El programa de servicios ambientales en áreas nacionales protegidas. 2012. Disponible en: <http://www.conanp.gob.mx/acciones/programa.php> Acceso en: 20 abr. 2007.

SOMUANO, Fernanda. Organizaciones civiles: formación y cambio. In: LOAEZA, Soledad; PRUD'HOMME, Jean Francois (Coords.). Instituciones y procesos políticos. México: El Colegio de México, vol. 14, 2010, p. 164-169.

TAPIA, Mónica. La otra agenda pendiente: leyes y políticas para una ciudadanía fuerte y organizada, 2011. México; Centro de Estudios Sociales y de Opinión Pública, p. 8-20. Disponible en: <http:// www.alternativasociales.org/node/530> Acceso en: 20 ene. 2013.

TOLEDO, A. Hacia una economía política de la biodiversidad y de los movimientos ecológicos comunitarios. Revista Chiapas, n. 6, 1998. Recuperado el 12 julio 2005 de: <http://www.ezln.org/ revistachiapas/TOLEDO6.html>.

VERDUZCO, Basilio. Contribuciones del ambientalismo a la movilización de la sociedad civil: un modelo interpretativo de la experiencia en la frontera México-Estados Unidos. Región y Sociedad, vol. XIII, n. 22, p. 1-44, 2001.

WORLD BANK. Advancing Sustainable Development. The World Bank and Agenda 21. Environmentally sustainable development Studies and Monographs, n. 19, 1997. 